\title{
Inhibitory Effect of Quassia amara Linn. Crude Bark Extract on Entamoeba histolytica in vitro
}

\author{
Jayson C. Panganiban, ${ }^{1}$ Annarose L. Patupat, ${ }^{1}$ Jose Antonio T. Paulino, ${ }^{1}$ Grace G. Penserga, ${ }^{1}$ \\ Mar Aristeo G. Poncio, ${ }^{1}$ Romeo V. Porlas Jr., ${ }^{1}$ Anna Sharmie C. Quezon, ${ }^{1}$ Hernane M. Quicho, ${ }^{1}$ \\ Everly Faith P. Ramos, ${ }^{1}$ Edgar F. Remonte, Jr., ${ }^{1}$ Julianne Francesca F. Reyes, ${ }^{1}$ Adovich S. Rivera, ${ }^{1}$ Kay C. Rivera, ${ }^{1}$ \\ Manuel Gregorio T. Rivera, ${ }^{1}$ Paolo Nico A. Rogelio, ${ }^{1}$ Hope M. Sagayaga III, ${ }^{1}$ Maria Carmina L. Santiago, ${ }^{1}$ \\ John Patrick See, ${ }^{1}$ Waldermar T. Siy, ${ }^{1}$ Faye S. Cagayan, ${ }^{2}$ Cecile C. Maramba ${ }^{2}$ and Pilarita T. Rivera ${ }^{3}$ \\ ${ }^{1}$ Ther 201 Research Group 7, College of Medicine, University of the Philippines Manila \\ 2 Department of Pharmacology and Toxicology, College of Medicine, University of the Philippines Manila \\ ${ }^{3}$ Department of Parasitology and Medical Entomology, College of Public Health, University of the Philippines Manila.
}

\begin{abstract}
Background. Entamoeba histolytica is an important etiologic agent of diarrhea. Globally, it is estimated to infect 40 to 50 million people and cause 40,000 to 100,000 deaths per year. $<$ local studies> Metronidazole is effective but can cause adverse reactions in certain individuals. In search of alternatives, traditional medicinal plants are being studied. Several plants in Family Simaroubaceae have shown anti-amoebic activity. Quassia amara, a member of this family, has not been tested.
\end{abstract}

Objective. To determine the effect of $Q$. amara crude extract on Entamoeba histolytica in vitro.

Methods. Initial testing of $10^{4} \mu \mathrm{g} / \mathrm{ml}$ ethanolic bark extract was performed. Counts were made after 72 hours. Three trials in triplicates were performed.

Nine (9) dilutions of the extract were then tested (18.8 to 5,000 $\mu \mathrm{g} / \mathrm{ml})$. Test tubes were checked for viable amoeba after 24 -hour and 72-hour incubation. Minimum inhibitory concentrations (MIC) were determined for the two incubation periods. At least two trials in triplicates for each dilution were performed. Metronidazole served as positive control.

Results. At $10^{4} \mu \mathrm{g} / \mathrm{ml}$ incubated for 72 hours, no viable amoeba was obtained and counted. The MIC after 24 hours was 5,000 $\mu \mathrm{g} / \mathrm{ml}$, while the MIC at 72 hours was $37.5 \mu \mathrm{g} / \mathrm{ml}$.

Conclusion. Q. amara crude extract has inhibitory effects on $E$. histolytica in vitro.

\section{Key Words: Quassia amara, antiprotozoal agents, anti-amebic}

Paper presented at the National Medical Students Conference 2011, April 2, 2011, Buenafe Auditorium, College of Medicine, University of the Philippines Manila.

Corresponding author: Adovich S. Rivera, MD

Institute of Health Policy and Development Studies

National Institutes of Health

University of the Philippines Manila

623 Pedro Gil St., Ermita, Manila 1000 Philippines

Telephone: +632 5264349

Email: adovich.rivera@gmail.com

\section{Background}

Amoebiasis is an important cause of parasite-related diarrhea especially in countries where living conditions and sanitary systems are inadequate. ${ }^{1}$ It is estimated to cause 40,000 to 100,000 deaths a year making it the third most important parasitic disease after malaria and schistosomiasis. ${ }^{2}$ The disease is caused by the parasite Entamoeba histolytica through its invasion of the intestinal wall. The parasite is frequently transmitted by way of the fecal-oral route and releases parasite-derived hyaluronidases and proteases upon reaching the intestines. These enzymes create ulcerating mucosal lesions that often result in amoebic dysentery and amoebic colitis. ${ }^{3}$ The parasite also affects other extraintestinal organs, mainly the liver such as in amoebic liver abscess. ${ }^{4}$

Globally, it is estimated to infect $10 \%$ of the population. ${ }^{5}$ At one point, it was estimated to kill 700,000 people. ${ }^{6}$ The global estimate dates back to 1986 and to date we have not found newer studies on the global burden of the disease. More recent local studies are however consistent with this estimate. In a study conducted by Sevilla and Cross $^{7}$ among fecal and serum samples collected from Luzon, Marinduque, Mindoro, Samar, Panay, and Palawan, 5\%-6\% tested positive for E. histolytica by direct fecal, concentration techniques, and indirect hemagglutination tests. Another local study by Rivera $\mathrm{W}$ et al. among households in an area of Northern Luzon showed that $8.119 \%$ having E. histolytica or E. dispar cysts. The same study utilized PCR techniques and showed found most cysts where E. dispar and E. histolytica are actually present in just $0.961 \%$ of that population. ${ }^{8}$

Saniel et al. ${ }^{9}$ recovered the parasite from 18 out of 339 (5\%) children and adults with acute diarrhea consulting at the Research Institute for Tropical Medicine (RITM) hospital from 1985 to 86.5. It is also implicated in amebic liver abscess patients of the Philippine General Hospital and Jose R. Reyes Memorial Medical Center especially in male patients aged 21-50 years old. ${ }^{10}$ 
Treatment of E. histolytica infection can be done through emetine or a nitroimidazole such as the usual choice, metronidazole. Though potent, they are not perfect drugs. Emetine exerts serious side effects by allowing high concentrations to build up in the liver, heart, and other viscera. ${ }^{6}$ Metronidazole, meanwhile, is noted to have various side effects such as nausea, bitter taste, epigastric discomfort, diarrhea, vomiting, fatigue, reversible neutropenia, and cutaneous hypersensitivity reactions. ${ }^{11}$ There are also case reports of peripheral neuropathy. ${ }^{12,13}$ In addition, nitroimidazoles as a class are genotoxic and cytotoxic to human lymphocytes as tested in vitro. ${ }^{14}$ Its use in pregnant and lactating women is also contraindicated due to some possibility of acting as a teratogen. ${ }^{15}$

With limited drug choices, drug resistance is an everpresent threat. Upcroft $\mathrm{P}$ and Upcroft $\mathrm{J}^{6}$ cited an unpublished report indicating an increasing number of isolates that are less sensitive to metronidazole in Chandigarh, India. They have also successfully induced resistance in laboratory grown amoeba. These warrant a continuous search for a drug that would balance safety and efficacy against $E$. histolytica.

Traditional medicinal plants are often used in search of lead compounds for new drugs. Several local studies have tested plants for anti-protozoal in general and anti-amebic properties in particular. Chromolaena odorata and Uncaria perrottetii were shown to have effects on the growth of two protozoans, Blastocystis hominis and Trichomonas vaginalis. ${ }^{16}$ Ficus septica, Sterculia foetida ${ }^{17}$ and Voacanga globosa ${ }^{18}$ have been shown to affect the growth of $T$. vaginalis and $E$. histolytica.

In this study, we look into the Family Simaroubaceae, members of which have been traditionally used in Mexico, China, and Ethiopia for the treatment of dysentery. ${ }^{19}$ Brucea antidysenterica, Brucea javanica fruits and seeds, and Simarouba amara stem $^{20}$ were previously tested and were found to be effective against E. histolytica. Plants from this family also contain the quassinoid compounds ailanthone and glaucarbine which showed potent activity against the dysentery amoeba, Entamoeba histolytica, both in vitro and in vivo. ${ }^{19}$

Quassia amara (also known as "korales") is a locally available member of Simaroubaceae. It is a perennial tree or shrub with small red-tinged flowers and red oval fruits. ${ }^{21}$ It is traditionally used as antipyretic, insect repellant, lice treatment, and anti-malarial. ${ }^{22}$ It has also been found to have insecticidal $^{23}$ properties and antiviral effects on the human immunodeficiency virus. ${ }^{24}$ Quassinoids from the plant and its relatives have been shown to have in vitro antimalarial activities. ${ }^{25}$ Searching databases like PubMed and Herdin.ph showed that this plant has yet to be tested for its antiamoebic activity. The anti-amoebic activity shown by the other family-related species may be a lead to finding other compounds found in $Q$. amara that could show the same activity against Entamoeba histolytica. The crude bark extract of $Q$. amara will be tested for anti-amoebic activity.

The life cycle of E. histolytica features two main morphologic forms: the lumen-dwelling trophozoite and the infective cyst. Notably, only trophozoite forms are observed in vitro. This phenomenon is useful in screening for the effects of substances against E. histolytica as it allows the use of simple light microscopy to differentiate viable from nonviable amoeba by considering only trophozoites as the viable amoeba. Inducing the cystlike structures in vitro requires special conditions and has been the subject of research. This state has been successfully induced in a recent study by Aguilar-Diaz et al. ${ }^{26}$ Their group also cited other alternative methods required the use of $\mathrm{CO} 2$, intestinal enzymes or enteric bacteria.

\section{Materials and Methods}

\section{Extract preparation}

The bark of Quassia amara Linn. was collected and identified by the botanist from the Jose Vera Santos Herbarium, Institute of Biology, UP Diliman. A voucher sample was also sent to the herbarium of the National Museum.

The bark was air-dried for two weeks, homogenized using an osterizer and then soaked in 95\% ethanol for 5 days. The mixture was filtered and the ethanolic filtrate was sent to the Department of Biochemistry and Molecular Biology, College of Medicine, University of the Philippines (UP) Manila for evaporation via rotary evaporator. A 5\% $(\mathrm{g} / \mathrm{mL})$ stock mixture of the extract prepared by dissolving the extract in TYI-S-33 medium. This mixture was then sterilized by passage through a $3.5 \mu \mathrm{m}$ microfilter. The crude extract and stock mixtures were stored at $4^{\circ} \mathrm{C}$.

\section{Microorganism}

E. histolytica HK-9 strain was obtained from the Molecular Protozoology Laboratory, Natural Science Research Institute, UP Diliman. The trophozoites were cultured axenically in complete medium or TYI-S-33 medium supplemented with $10 \%$ bovine serum, 40x Vit mixture and antibiotic (Pen-Strep) at $34.5{ }^{\circ} \mathrm{C}$

\section{Pilot Study}

A pilot study based on the procedure of Vital et al. ${ }^{17}$ was performed to screen for the effect of $Q$. amara crude extract on the viability of E. histolytica. The amoebae were subjected to three treatments: (1) $1 \%\left(10^{4} \mu \mathrm{g} / \mathrm{ml}\right) Q$. amara crude extract (2) positive control (metronidazole at $17.1 \mu \mathrm{g} / \mathrm{ml}$ ), (3) negative control or blank containing complete medium described in the previous section. Amoebae, at a concentration of $1.0 \times 10^{3}$ cells $/ \mathrm{ml}$, were incubated at $34.5^{\circ} \mathrm{C}$ for 72 hours. 
After 24 hours of incubation, tubes were viewed under scanning view of light microscope to check for viable amoebae. After 72 hours, the concentration of viable amoebae was determined using a Neubauer counting chamber. Counters were blinded to the treatment groups. Each treatment was done in triplicate. Three trials on three separate occasions were performed.

\section{Anti-amebic assay}

To determine the minimum inhibitory concentration (MIC), amoebae $\left(10^{3}\right.$ cells $\left./ \mathrm{mL}\right)$ were cultured with various concentrations $(5,000,2,500,1,300,600,300,150,75,37.5,18.8$ $\mu \mathrm{g} / \mathrm{ml}$ ) of $Q$. amara extract. After 24-hour and 72-hour incubation, the tubes were scanned for living amoebae. In similar studies, peak number of viable amoebae or growth was noted at 72 hours of incubation and the point where the effect of any substance on growth and viability would probably be most apparent. Results were reported as positive or negative for viable amoebae. Viewing and assessment of tubes were performed under the supervision of the research staff of Department of Parasitology of the College of Public Health.

Viable amoebae (Figure 1a) were distinguished from nonviable amoebae (Figure $1 \mathrm{~b}$ ) by the three criteria: shape, attachment, and motility. Amoebae need to meet the three criteria in order to be labeled viable. Viable amoebae are generally ovoid but can be pleomorphic. They are motile and have a finer granular texture (as if filled with sand). In general, nonviable amoebae resemble cyst-like structures being spherical with a coarse granular texture but do not contain nucleoli. They are often found floating in the medium. During assessment, only viable amoebae were considered (Table 1, Figure 1). Wong et al. ${ }^{27}$ also described viable amoebae similarly in their study using E. histolytica.

MIC is the lowest tested concentration wherein no viable amoebae was detected upon viewing of the tubes. Two MICs were determined, one for 24 hours (MIC24) and one for 72 hours (MIC72). At least two trials were performed for each concentration. Treatments per trial were performed in triplicate.

Determining the effect of ethanol on the viability of amoebae was necessary since it was the solvent used to obtain the crude extract. To check the effect of ethanol, amoebae were cultured with ethanol at a concentration equal to the determined MIC24.

Blank tubes are tubes where ameobae are grown in complete medium only. In tubes containing extract, ethanol or metronidazole, the amount of nutrient broth used was reduced by the volume of extract solution needed in order to maintain a maximum volume of $8.0 \mathrm{ml}$. Volume of nutrient broth was also adjusted according to the volume of amoeba inoculum needed. Maximum inoculum volume limit was set at $2.0 \mathrm{ml}$.
Table 1. Criteria for Differentiating Viable and Nonviable Amoeba

\begin{tabular}{lll}
\hline & Viable & Nonviable \\
\hline Shape & $\begin{array}{l}\text { Ovoid or } \\
\text { pleomorphic }\end{array}$ & Round or Spherical \\
Motility & Motile & Non-motile \\
$\begin{array}{l}\text { Attachment To Test } \\
\text { tube wall }\end{array}$ & Attached & $\begin{array}{l}\text { Usually floating in } \\
\text { singles or clumps }\end{array}$ \\
\hline
\end{tabular}

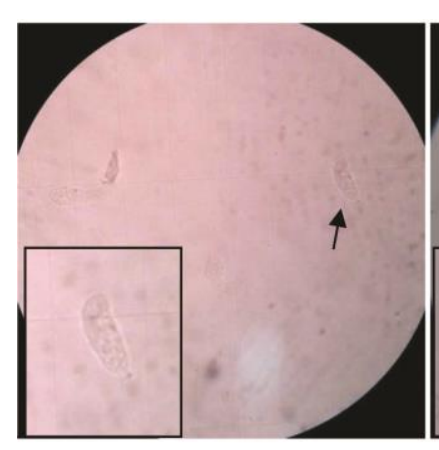

A

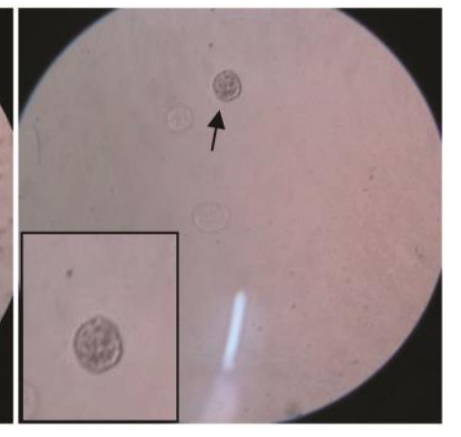

B
Figure 1. Morphology of viable and nonviable $E$. histolytica trophozoites (arrows) (100x). E. histolytica (arrows) loaded into counting chamber. Blown-up images of the amoeba are placed in the lower left corner. A is viable amoeba while B is nonviable. Viable amoeba are generally ovoid but can be pleomorphic. They are motile and have a finer granular texture. Nonviable amoeba are spherical with a coarse granular texture.

\section{Disposal}

After the experiment, Inoculated media, test tubes, and other materials were autoclaved. Media was then collected and disposed with other infectious waste of the Department of Medical Microbiology of the College of Public Health.

\section{Results}

One percent (1\%) Q. amara extract inhibited the growth of E. histolytica after incubation for 72 hours. At 24 hours, no viable amoeba was detected in the $1 \% Q$. amara and metronidazole on scanning of tubes under light microcope. Mean growth in the blank tube was 1,853 cells/ml (SD: 1821) after 72 hours. No amoeba was loaded into the counting chamber for both $1 \% Q$. amara and Metronidazole.

Table 2 shows the results of incubation of amoebae with the extract after 24 hours and 72 hours. MIC24 is 5,000 ug/ml and MIC72 is $37.5 \mathrm{ug} / \mathrm{ml}$. Viable amoebae were detected after 24-hour incubation at tested concentrations less than $5,000 \mu \mathrm{g} / \mathrm{ml}$ and after 72 hours at $18.8 \mu \mathrm{g} / \mathrm{ml}$. The tubes at these concentrations were not highly colored by the extract (Figure 2). 
Table 2. Growth and $\mathrm{pH}$ in different dilutions of $Q$. amara crude extract (in $\mu \mathrm{g} / \mathrm{ml}$ )

\begin{tabular}{|c|c|c|c|c|c|c|c|c|c|c|c|c|c|}
\hline & Blank & EtOH & Met & $10^{4}$ & 5000 & 2500 & 1300 & 600 & 300 & 150 & 75 & 37.5 & 18.8 \\
\hline $24 \mathrm{~h}$ & + & + & - & - & - & $+^{*}$ & $+^{*}$ & $+^{*}$ & + & + & + & + & + \\
\hline $72 \mathrm{~h}$ & + & + & - & - & - & - & - & - & - & - & - & - & + \\
\hline $\mathrm{pH}$ & 6.98 & $\#$ & \# & 6.95 & 6.97 & 6.96 & 6.95 & 6.97 & 6.81 & 6.97 & 6.98 & 6.82 & 6.98 \\
\hline
\end{tabular}

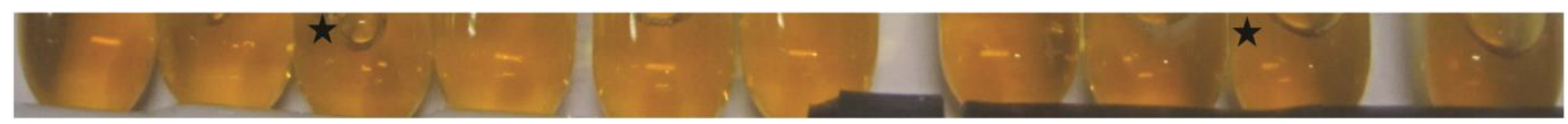

Figure 2. Dilutions of $Q$. amara crude extract in complete medium. Tubes are arranged from least concentrated (blank, 0 $\mu \mathrm{g} / \mathrm{ml})$ to most concentrated $(1,000 \mu \mathrm{g} / \mathrm{ml})$. Marked tubes are those at MIC concentrations, the first marked tube from the left is MIC $72(37.5 \mu \mathrm{g} / \mathrm{ml})$ and the second is MIC $24(5,000 \mu \mathrm{g} / \mathrm{ml})$.

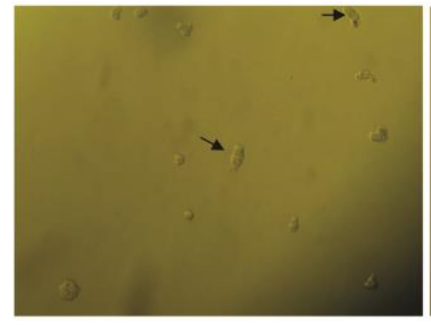

a

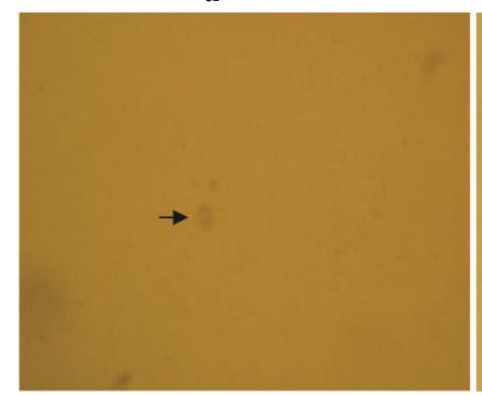

C

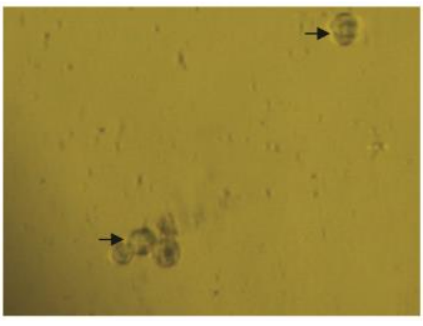

b

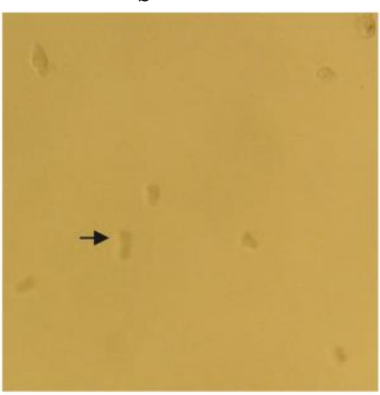

d
Figure 3. Amoeba grown under different conditions (100x). Arrows point to some of the amoeba in the picture. (a) Amoeba in blank $(0 \mu \mathrm{g} / \mathrm{ml})$ tubes after $72 \mathrm{~h}$ Under scanning lens, amoeba are refractile oval or amorphous motile bodies attached to the test tube walls. Amoeba are found in the bottom part of the test tube due to preference for microaerophilic conditions. (b) Nonviable amoeba in 5,000 $\mu \mathrm{g} / \mathrm{ml}$ after $72 \mathrm{~h}$. No change in shape was observed. (c) Viable Amoeba in 2,500 $\mu \mathrm{g} / \mathrm{ml}$ after 24h. Growth was sluggish. (d) Viable amoeba in ethanol $(600 \mu \mathrm{g} / \mathrm{ml})$ after $72 \mathrm{~h}$.

It should be noted that in one replicate of the 5,000 $\mu \mathrm{g} / \mathrm{ml}$, there were traces of attached nonviable amoebae. They were assessed as nonviable because of the lack of motility and difference in the texture of the cells (Figure 3b).
At $2500 \mu \mathrm{g} / \mathrm{ml}$, the amoebae were noted to be very sluggish and less ovoid in shape (Figure 3c) compared to blank tubes (Figure 3a). One replicate had no detectable amoeba. At 600 and $1,300 \mu \mathrm{g} / \mathrm{ml}$, there seemed to be less viable amoebae compared to the negative control. There were also replicates that had no detectable amoeba. Based on the scan, less viable amoebae were also seen at $18.8 \mu \mathrm{g} / \mathrm{ml}$ compared to the negative control. The difference not confirmed via quantification.

The evaluation of the effect of ethanol on amoebic growth was done qualitatively. There were viable amoebae in ethanol $(600 \mu \mathrm{g} / \mathrm{ml})$ both after 24 hours and 72 hours of incubation. The morphology of amoebae incubated in ethanol was the similar to the blank tubes (Figure 3d). The level of growth in ethanol seemed lower than that in the blank tubes; however, the difference was not quantified using the counting chamber because there was difficulty loading the amoeba despite multiple attempts.

Percent yield using bark of Q.amara was $2.604 \%$. Most of the $\mathrm{pH}$ of the dilutions lie in the range of 6.95-6.98. The dilutions 300 and $37.5 \mu \mathrm{g} / \mathrm{ml}$, had a $\mathrm{pH}$ of 6.81 and 6.82, respectively.

\section{Discussion}

Results showed that $Q$. amara crude bark extract may have anti-amoebic activity specifically on motility, shape and attachment. This activity may be due to several quassinoid compounds such as simaliklactone D, picrasin B, picrasin $\mathrm{H}$, neoquassin, quassin, picrasin I, and picrasin J. ${ }^{25}$ This finding strengthens the claim that members of Simaroubaceae have anti-amoebic activity. Q,amara has been found to be active in vivo against Plasmodium berghei. ${ }^{28,29}$ This anti-malarial activity was attributed to simalikalactone D. ${ }^{30}$ This supports the observation of Wright et al. ${ }^{20}$ that antiamoebic property parallels with anti-malarial property. 
We hypothesize that the extract has effects on the motility of the amoebae and their ability to undergo division. This would explain the difference in growth in extract-containing media compared to blank tubes. The hypothesized effects also explain the sluggish movement observed at 24 hours after incubation with $600-1,300 \mu \mathrm{g} / \mathrm{ml}$ extract.

Changing the $\mathrm{pH}$ and osmotic pressure of the external environment can adversely affect the growth, motility, and survival of amoeba. These changes, though, are insufficient to explain continued inhibition of growth at lower concentrations tested. The $\mathrm{pH}$ is not related to extract concentration, making it an insignificant factor. Increased osmotic pressures and turbidities may cause cell lysis or other cellular changes, but concentrations that are not turbid or grossly indistinguishable with the negative control also show anti-amoebic activity.

Since the extract was not lyophilized, traces of ethanol might still be present. One study ${ }^{20}$ showed that ethanol has no inhibitory effect on amoebic growth at $0.25 \%$ concentration. Similarly, our results show that ethanol at $5,000 \mu \mathrm{g} / \mathrm{ml}$ is not sufficient to kill amoeba. However, it still seems to exert some inhibitory effect in our case. Although the level of ethanol tested would not reflect what is actually in the extract, we established that ethanol can affect growth but is insufficient to kill all amoeba. Whether the extract without ethanol can inhibit amoebic growth cannot be conclusively shown through this study but the extract seems to be a necessary factor in inhibiting growth and causing amoebic death. The actual amount of ethanol contained in the crude extract is expected to be less than that in the ethanol only treatment. We observed that in the ethanol only set-up, there was still positive amoebic growth. Therefore, it is valid to attribute the death of amoeba in the crude extract treatment to the extract itself. Testing the lyophilized extract can also be done to conclusively prove that the extract alone has anti-amebic activity.

\section{Limitations}

We were unable to quantify the effect of the extract on the growth of amoeba. Similar studies such as those of Cedillo-Rivera et al. ${ }^{31}$ and Vital and Rivera ${ }^{17}$ often determine the IC50 for plant extracts and substances but this requires quantification of amoeba or plotting of growth curves through the period of incubation. However, the group found it difficult to grow sufficient amoeba that can allow reliable determination using counting chambers. We also had experiences that despite observing a number of living amoebae attached to the test tube walls, no amoebae was loaded into the counting chamber. If this quantification technique was used, amoeba concentrations of zero will be used to describe even replicates that have visually confirmed living amoebae. Due to this, we opted to use MIC since it relies only on the presence or absence of trophozoites in the test tubes.

\section{Conclusion and Recommendations}

Q. amara crude extract may have anti-amoebic properties against Entamoeba histolytica trophozoites in vitro. MIC24 is 5,000 $\mu \mathrm{g} / \mathrm{ml}$ and MIC72 is $37.5 \mu \mathrm{g} / \mathrm{ml}$.

As bark is not a sustainable source of the extract, it is recommended to test the leaves of Q.amara for anti-amoebic activity. Future studies can focus on determining the IC50 of the extract and its active fractions and molecules. It is also suggested to employ high throughput methods such as the microdilution method used by Wright et al..$^{20}$ for these future in vitro studies. Dye exclusion techniques such as the used by Radvin and Skilogiannis ${ }^{30}$ can be used to aid in identification of viable from non-viable trophozoites. In other studies also, viability was confirmed not just by microscopy but by subculture method which assesses if the amoeba retained ability to multiply. These types of methods may be able to address the limitations in quantification we encountered. In vivo testing can also be performed using the crude extract. Studies on the possible mechanisms of action can also be performed.

\section{References}

1. Sodeman WA Jr. Intestinal Protozoa: Amebas. In: Baron S, editor. Medical Microbiology [Online]. 4th edition. Galveston (Texas): University of Texas Medical Branch at Galveston; 1996. [cited 2010 July 26]. Available from: http://www.ncbi.nlm.nih.gov/books/NBK7742/.

2. Van Hal SJ, Stark DJ, Fotedar R, Marriott D, Ellis JT, Harkness JL. Amoebiasis: current status in Australia. Med J Aust. 2007; 186(8):412-16.

3. World Health Organization, Amoebiasis [Online] 2006 [cited 2010 July 26]. Available from: http://www.who.int/vaccine_research/diseases/ soa_parasitic/en/index1.html.

4. Ximenez C, Cerritos R, Rojas L, et al. Human amebiasis: breaking the paradigm? Int J Environ Res Public Health. 2010; 7(3):1105-20.

5. Walsh JA. Problems in recognition and diagnosis of amebiasis: estimation of the global magnitude of the morbidity and mortality. Rev Infect Dis. 1986; 8:228-38. In: ximenez C, Moran P, Rojas L, Valadez A, Gomez A. Reassessment of the epidemiology of amebiasis: state of the art. Infect Genet Evol. 2009; 9:1023-32.

6. Upcroft P, Upcroft, JA. Drug targets and mechanisms of resistance in the anaerobic protozoa. Clin Microbiol Rev. 2001;14(1):150164.

7. Cross JH, Basaca-Sevilla V. Seroepidemiology of amebiasis in the Philippines. Phil Soc Microbiol Infect Dis J. 1980; 9:21-6.

8. Rivera W, Tachibana H, Kanbara H. Field study on the distribution of Entamoeba histolytica and Entamoeba dispar in the Northern Philippines as detected by the Polymerase Chain Reaction. Am J Trop Med Hyg. 1998; 59(6):916-21.9. Saniel MC, Moriles RR, Monzon OT, et al. The relative importance of various enteropathogens in the etiology of acute diarrhea: A hospital-based study in urban Philippines. In Proceedings of the $14^{\text {th }}$ SEAMIC Workshop on Gastrointestinal Infections in Southeast Asia (V), Technical Meeting of Counterparts on SEAMIC Data Exchange Program on Infectious Diseases, Southeast Asia Medical Information Center, Japan 1988: 91-96. In Salazar NP, Pasay CJ, Avenido AO, et al. Detection of Entamoeba histolytica in routine stool examination. Phil J Microbiol Infect Dis. 1990; 19(23):57-60.

10. Rivera PT, Rivera WL, Escueta AS, et al. Prevalence of serologically positive amebic liver abscess cases in the Philippines. Acta Med Philipp. 2007; 41(2):31-6. 
11. Kasten MJ. Clindamycin, metronidazole, and chloramphenicol. Mayo Clin Proc. 1999; 74(8):825-33.

12. Gupta BS, Baldwa S, Verma S, Gupta JB, Singhal A. Metronidazole induced neuropathy. Neurol India. 2000; 48(2):192-3.

13. Bradley WG, Karlsson IJ, Rassol CG. Metronidazole neuropathy. Br Med J. 1977; 2(6087):610-1.

14. Lopez Nigro MM, Carballo MA. Genotoxicity and cell death induced by tinidazole (TNZ). Toxicol Lett. 2008; 180(1):46-52. In Siddique YH, Ara G, Beg T, et al. Protective effect of curcumin against the genotoxic damage induced by tinidazole in cultured human lymphocytes. Acta Pharm Sci. 2010; 52:23- 30.

15. Rosenthal PJ. Antiprotozoal Drugs. In: Katzung BG, Masters SB, Trevor AJ, eds. Basic and Clinical Pharmacology, $11^{\text {th }}$ ed. Singapore, Singapore: McGraw-Hill; 2009.

16. Vital PG, Rivera WL. Antimicrobial activity and cytotoxicity of Chromolaena odorata (L. f.) King and Robinson and Uncaria perrottetii (A. Rich) Merr. Extracts. J Med Plants Res. 2009; 3(7):511-18.

17. Vital PG, Velasco RN, Demigilio JM, Rivera WL. Antimicrobial activity, cytotoxicity and phytochemical screening of Ficus septica Burm and Sterculia foetida L. leaf extracts. J Med Plants Res. 2010; 4(1):058-063.

18. Vital PG, Rivera WL. Antimicrobial activity, cytotoxicity, and phytochemical screening of Voacanga globosa (Blanco) Merr. leaf extract (Apocynaceae). Asian Pac J Trop Med. 2011; 4(10):824-8.

19. Gillin FD, Reiner DS, Suffness N. Bruceantin, a potent amebicide from a plant, Brucea antidysenterica. Antimicrob Agents Chemother. 1982; 22(2):342-5.

20. Wright CW, O'Neill MJ, Phillipson JD, Warhurst DC. Use of microdilution to assess in vitro antiamoebic activities of Brucea javanica fruits, Simarouba amara stem, and a number of quassinoids. Antimicrob Agents Chemother. 1988; 32(11):1725-9.

21. Ridgway A. Approved Recovery Plan Quassia sp. Mooney Creek (Moonee Quassia) [Online]. New South Wales, Australia: Department of Environment and Conservation (New South Wales, Hurstville); 2005 [cited 2011 January 3] 25 p. Available from: http://www.environment.nsw.gov.au/resources/ nature/recoveryplanMooneequassia Jul05.pdf.
22. DeFilipps RA, Maina SL, Crepin J. Medicinal Plants of the Guianas (Guyana, Surinam, French Guiana) [Online]. Washington: Smithsonian National Museum of Natural History; 2004 [cited 2011 January 3]. 477 p. Available from: http://botany.si.edu/bdg/medicinal/index.html

23. Flores G, Hilje L, Mora GA, Carballo M. Antifeedant activity of botanical crude extracts and their fractions on Bemisia tabaci (homoptera: Aleyrodidae) adults: III. Quassia amara (Simaroubaceae). Rev Biol Trop. 2008; 56(4):2131-46.

24. Abdel-Malek S, Bastien JW, Mahler WF, et al. Drug leads from Kallawaya herbalists of Bolivia. 1. Background, rationale, protocol and anti-HIV activity. J Ethnopharmacol. 1996; 50(30):157-66.

25. O'Neill MJ, Bray DH, Boardman P, et al. Plants as sources of antimalarial drugs: in vitro antimalarial activities of some quassinoids. Antimicrob Agents Chemother. 1986; 30(1):101-4.

26. Aguilar-Diaz H, Diaz-Gallardo M, Laclette JP, Carrero JC. In vitro induction of Entamoeba histolytica cyst-like structures from trophozoites. PLoS Negl Trop Dis. 2010; 4(2):e607.

27. Wong WK, Tan ZN, Lim BH, Mohamed Z, Olivos-Garcia A, Noordin R Comparison of protein-free defined media, and effect of L-cysteine and ascorbic acid supplementation on viability of axenic Entamoeba histolytica. Parasitol Res. 2011; 108(2):425-30.

28. Ajaiyeoba EO, Abalogu UI, Krebs HC, Oduola AM. In vivo antimalarial activities of Quassia amara and Quassia undulata plant extracts in mice. J Ethnopharmacol. 1999; 67(3):321-5

29. Houël E, Bertani S, Bourdy G, et al. Quassinoid constituents of Quassia amara L. leaf herbal tea. Impact on its antimalarial activity and cytotoxicity. J Ethnopharmacol. 2009; 126(1):114-8.

30. Bertani S, Houël E, Stien D, et al. Simalikalactone D is responsible for the antimalarial properties of an Amazonian traditional remedy made with Quassia amara L. (Simaroubaceae). J Ethnopharmacol. 2006;108:155-7.

31. Cedillo-Rivera R, Chavez B, Gonzales-Robles A, Tapia A, Yépez-Mulia L. In vitro effect of Nitazoxanide against Entamoeba histolytica, Giardia intestinalis and Trichomonas vaginalis trophozoites. J Eukaryot Microbiol. 2002; 49(3):201-8

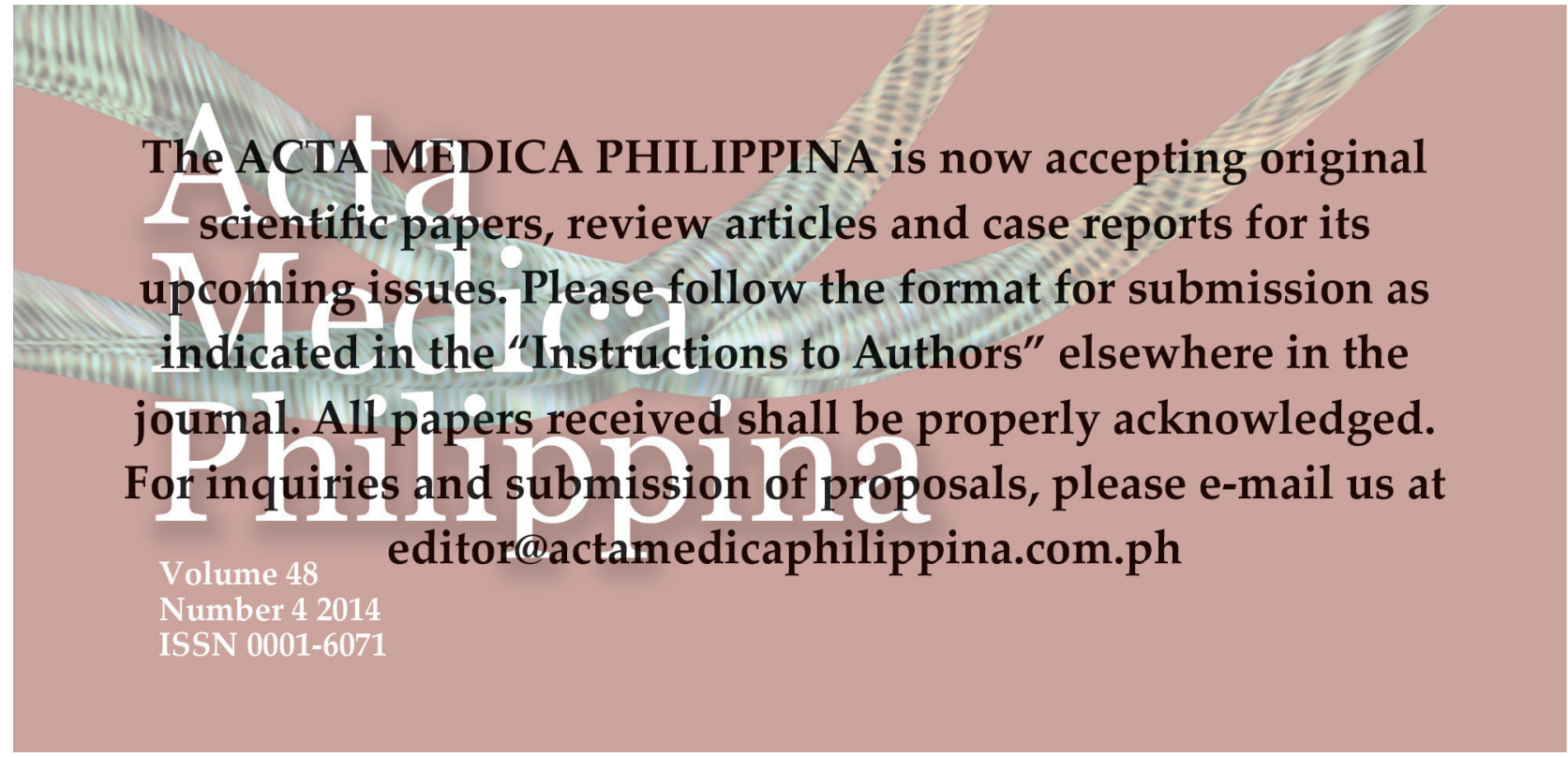

